Relations industrielles

Industrial Relations

\title{
Le syndicalisme en contexte socialisé
}

\section{Louis-Marie Tremblay}

Volume 18, numéro 2, avril 1963

URI : https://id.erudit.org/iderudit/1021435ar

DOI : https://doi.org/10.7202/1021435ar

Aller au sommaire du numéro

\section{Éditeur(s)}

Département des relations industrielles de l’Université Laval

ISSN

0034-379X (imprimé)

1703-8138 (numérique)

Découvrir la revue

Citer ce document

Tremblay, L.-M. (1963). Le syndicalisme en contexte socialisé. Relations industrielles / Industrial Relations, 18(2), 272-273.

https://doi.org/10.7202/1021435ar
Résumé de l'article

La socialisation se présente dans une situation de développement technologique rapide qui transforme la structure de la main-d'oeuvre et pose des problèmes dont la solution ne peut être trouvée qu'au niveau des grands ensembles économiques, ce qui nécessite l'intervention de l'Etat.
Tous droits réservés (C Département des relations industrielles de l’Université Laval, 1963
Ce document est protégé par la loi sur le droit d'auteur. L’utilisation des services d'Érudit (y compris la reproduction) est assujettie à sa politique d'utilisation que vous pouvez consulter en ligne.

https://apropos.erudit.org/fr/usagers/politique-dutilisation/ 


\title{
LE SYNDICALISME EN CONTEXTE SOCIALISÉ
}

\section{Ls-M. Tremblay}

\begin{abstract}
La socialisation se présente dans une situation de développement technologique rapide qui transforme la structure de la main-d'oeuvre et pose des problèmes dont la solution ne peut être trouvée qu'au niveau des grands ensembles économiques, ce qui nécessite l'intervention de l'Etat.
\end{abstract}

\section{RôLE DE L'Etat}

L'extension du rôle de l'Etat est l'une des principales caractéristiques de la socialisation. L'Etat de bien-êtré, employeur, planificateur est de plus en plus engagé dans le domaine des relations du travail. Par certaines législations du travail et les mesures de sécurité sociale, il devient un concurrent des groupes économiques. C'est pourquoi, la prise de décision, en relations industrielles, est de plus en plus socialisée et le syndicalisme est soumis à certains contrôles communautaires.

\section{RôLE DES SYNDICATS}

Face à la socialisation, le syndicalisme peut opter pour une attitude négative et retourner vers des formes d'action syndicale qui se justifiaient dans un contexte de libéralisme économique.Il peut se laisser absorber par l'Etat et devenir, comme le syndicalisme soviétique, un organe d'encadrement des masses laborieuses. Mais, l'option la plus logique est celle d'une intégration démocratique, où le syndicalisme conserve ses fonctions traditionnelles en effectuant des adaptations idéologiques et structurelles qui s'imposent pour rencontrer efficacement les exigences des réalités nouvelles. Tout en conservant son indépendance, il remplit alors, vis-à-vis le pouvoir politique, la double fonction de participation et de contrôle. D'autre part, dans le domaine économique, la négociation collective demeure sa responsabilité première.

\section{LA CONVENTION COLLECTIVE}

Mais dans un contexte de socialisation avancée, la convention collective est appelée à subir des modifications profondes. Son contenu sera de plus en plus complexe et étendu. La négociation s'effectuera au niveau industriel ou multiindustriel. Le contrat collectif servira, en quelque sorte, d'auto-gouvernement de l'industrie et exigera des contacts étroits et continus, systématisés et professionnalisés entre les représentants des divers agents de l'économie. Dans les rapports collectifs, un caractère public sera substitué au caractère privé.

\section{Transformation DU SYNDICALISME}

Face à cette réalité, le syndicalisme subira une phase d'adaptation nécessitant des aménagements structurels et des modifications, au point de départ, de certains postulats propres à une économie libérale, auxquels il a jusqu'ici donné son consensus. Les options et les comportements devront être conçus suivant une 
perspective communautaire plutôt qu'une perspective micro-économique. De plus, les divers mouvements syndicaux auront à développer des formules de coopération afin de réaliser une communauté minimum d'attitudes, prérequise pour une action solidaire dans un contexte socialisé.

Une consolidation des structures suivra. Le pouvoir sera centralisé vers le haut. Les unions deviendront moins nombreuses, mais plus larges et plus englobantes. Elles seront centrées sur un procédé technologique de production plutôt que sur le métier ou le produit. Le rôle des locaux sera transformé. Ils conserveront peu de pouvoir de prise de décision. Ils serviront d'agence d'information et d'exécution, de canal de communication et d'instrument de contrôle.

\section{LA GRÈVE}

La grève prendra un sens nouveau et de nouvelles formules de solution des conflits devront être trouvées. La mise sur pied de bureaux de recherche et l'incorporation dans les rangs syndicaux de chercheurs spécialisés s'imposeront afin que le syndicalisme puisse faire face adéquatement à la complexité et à l'ampleur des problèmes qui seront soulevés.

\section{Conclusion}

Le processus de socialisation semble inéluctable. Mais il s'imposera graduellement en laissant place aux adaptations nécessaires. Mais, si le syndicalisme entend continuer de jouer un rôle de premier ordre et ne pas se laisser supplanter par l'Etat, il doit accepter le phénomène de la socialisation et se préparer en conséquence.

\section{LE RÓLE de L'ETAT EN RELATIONS DU TRAVAIL - ESSAI DE REÉVALUATION}

Me Jean-R al Cardin

\section{INTRODUCTION}

Il s'agit pour nous de considérer notre système de relations industrielles et d'y étudier le rôle de l'Etat en tant que troisième participant à ce système.

Il est tout particulièrement urgent, pour nous du Québec, de reprendre à notre compte l'étude du rôle de l'Etat en matière de relations du travail si nous ne voulons pas être dépassés par les événements, car même si le Québec est fonction, dans une large mesure, de ce qui en relations industrielles nous vient du Canada anglais et des Etats-Unis, il n'en reste pas moins que l'état de notre économie et les retards 